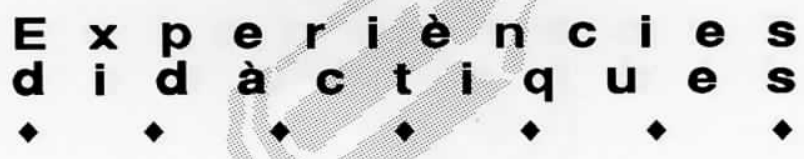

\title{
Nous mitjans per a vells problemes: matemàtiques i alguns recursos TIC
}

\author{
Luisa Girondo. Didàctica de la Matemàtica. Universitat Rovira i Virgili
}

\begin{abstract}
Resum:
Les tecnologies de tractament de la informació estan canviant el panorama escolar, fins i tot d'una manera tan ràpida que no deixa temps a la reflexió serena d'avantatges i inconvenients. En el cas de l'àrea de matemàtiques, aquests canvis són profunds i, si es fan de manera encertada, es valoren com a molt positius. Aquest article fa una reflexió al voltant d'alguns recursos TIC per millorar la competència matemàtica bàsica.
\end{abstract}

\section{Paraules clau:}

Educació matemàtica, competència, recursos a la xarxa, visualització

\section{Introducció}

Preparar les noves generacions per inserir-se socialment i progressar ha representat i representa per a les autoritats educatives, les famílies $\mathrm{i}$, en general, per a diversos actors socials un vell problema, que té en la selecció d'objectius adients, en la manera d'organitzar la formació i en el plantejament de quins recursos dedicar-hi, els principals elements de discussió de cara a prendre les decisions que siguin més encertades. Generacions anteriors han hagut de plantejar-se el mateix problema i han considerat les condicions tecnològiques $\mathrm{i}$ ambientals del moment per fer els seus plantejaments d'acció. Ara estem en una etapa de canvis importants $i$, per tant, és lògic replantejar-se de nou què es fa perquè les noves generacions siguin competents en una societat tecnològicament avançada.

Els estudis sobre aprenentatge ens aporten informacions, i fins i tot teories, sobre com els humans aprenem i quina influència tenen en aquest aprenentatge les pràctiques socials de l'entorn o de l'època en què ens ha tocat viure. Avui dia, moltes pràctiques socials han canviat notablement a causa de l'impacte que tenen les tecnologies denominades de la informació i la comunicació. Crec que es pot afirmar que estem davant de nous "mediadors culturals" que tindran certa influència en la programació de la "nova ment de l'Emperador", per citar el llibre de R. Penrose (1991). Ja que el nostre cervell es deixa enganyar tant fàcilment (Wassenberg, 2004), ens podem preguntar: quin paper tindrà el món virtual en la formació de la visió del món que es fan les noves generacions? No és intenció d'aquest article fer previsions al voltant de futurs incerts, sinó simplement fer una reflexió al voltant de l'educació matemàtica que ja hem de fer ara per al ciutadà del demà.

Sobre la matemàtica com a disciplina escolar, els currículums sempre han parlat del doble objectiu formatiu i instrumental, com volent dir que la matemàtica és necessària en l'escolaritat bàsica per raons instrumentals, ja que ens dóna conceptes i procediments d'ús pràctic en diverses situacions de context real (calcular, mesurar, informació numèrica, representacions de l'espai...) i per l'aprenentatge d'altres disciplines (representacions espacials i estadístiques per la geografia, llenguatge algèbric i funcional per la física, formes i propietats pel disseny...). A més, és formativa, ja que aporta maneres de fer, de captar els invariants o de controlar els canvis d'una situació i descriure'ls fent servir representacions i codis sintètics, cosa que implica capacitat d'establir relacions, captar analogies, fer induccions..., aspecte que se simplifica dient "ensenya a pensar" o "ajuda a estructurar el pensament".

Avui dia, no es fa tant aquesta distinció dels rols educatius de la disciplina, ja que s'entén que tots dos estan inclosos en considerar no la "instrucció en matemàtiques" (disposar d'unes tècniques aplicables a situacions diverses), sinó "I'educació en matemàtiques", entesa ja com l'amalgama 


\section{Ex}

entre maneres de pensar i fer pròpies de la disciplina, juntament amb l'adquisició de conceptes i procediments útils que constitueixen les destreses bàsiques necessàries per al ciutadà.

\section{L'educació matemàtica del ciutadà}

L'educació matemàtica del ciutadà es descriu ara en termes de competència matemàtica. Fent cas de la proposta del Consell i la Comissió Europea, la formulació actual del currículums obligatoris de diferents països inclouen la competència matemàtica bàsica, juntament amb altres set competències bàsiques, com un objectiu del treball escolar.

Convé ser realistes per no generar falses expectatives $i$ distingir ja d'entrada el que seria la competència matemàtica d'un professional de la matemàtica (o d'un professional que la utilitzi com a llenguatge bàsic del seu camp professional) i la competència matemàtica bàsica, referida a la competència matemàtica necessària per entendre el món i prendre decisions amb criteri com a ciutadà responsable.

Per aclarir aquesta terminologia acceptarem la següent definició per a competència matemàtica bàsica de la Comissió i el Consell d’Europa:
"La competència matemàtica és I'habilitat per desenvolupar i aplicar el raonament matemàtic amb la finalitat de resoldre diversos problemes en situacions quotidianes. Basant-se en un bon domini del càlcul, l'èmfasi se situa en el procés i l'activitat però també en els coneixements. La competència matemàtica comporta - en diferents graus - la capacitat i la voluntat d'utilitzar maneres de pensar pròpies de les matemàtiques (pensament lògic $i$ pensament espacial) i formes de representació característiques (fórmules, models, construccions, gràfics i diagrames)". (1)

Aquesta idea forma part ara, doncs, dels currículums obligatoris. No es pot fer, per tant, una lectura precipitada dels continguts de l'àrea curricular i interpretar alguna cosa així com "aquest curs toca la resta, aquest curs el càlcul d'àrees, aquest curs les equacions de 1 r grau...." $i$ pensar que donant tècniques i simbologia, per un procés màgic, l'alumne, en tenir certes eines, veurà ràpidament les múltiples funcionalitats i desenvoluparà la capacitat( $\mathrm{i}$ la voluntat) de mobilitzar-les de manera adient davant de la situació problemàtica.

Una comunicació recent d'un professor xinès de matemàtiques formulava el que es diu al seu país, la famosa dita atribuïda a Confuci: "Dóna un peix a un home i en té per un dia; ensenya-li a pescar i es podrà alimentar sempre", que en versió d'educació matemàtica actualitzen dient "Memoritza una fórmula i passa l'examen; comprèn la fórmula i descobreix la utilitat en situacions diverses que et trobaràs a la vida".

Estem ara, doncs, davant del repte d'ajudar als alumnes a assolir certa competència matemàtica. I aquesta obliga a considerar el saber fer d'una determinada manera, a més de cercar comprensió profunda dels conceptes i dels procediments que al llarg de les generacions s'han revelat útils per tractar problemes diversos. A més, l'alumne ha de desenvolupar una actitud positiva davant d'aquests aprenentatges per tenir voluntat d'utilitzar-los quan calgui.

\section{La competència i la pràctica d'aula}

És clar que la competència es nodrirà de sabers de diferents tipus. La matemàtica escolar és un d'aquells aprenentatges essencials que es dóna fonamentalment en el marc escolar. Pel tipus de contingut que treballa, el podem considerar un llenguatge que porta al darrere una manera de pensar (ara el currículum sembla que prefereix considerar-la com a competència metodològica... Segurament té raó el professor Niss (1998) quan afirma que la indisputabilitat d'aquesta disciplina en tots els currículums de tots els temps és degut a la gran "potencialitat", ja que les matemàtiques són diverses coses alhora!). Però no és fàcil aprendre-les d'una manera "informal" (fóra de l'aula) i s'arriba a l'escola amb molt poca pràctica social que creï les bases intuïtives a partir de les quals construir significats adients. Per tant, som els professors els que hem de triar els contextos adequats $i$ les representacions adients que permetin que els alumnes donin sentit a números, càlculs, formes, models... per tal de connectar el llenguatge matemàtic amb els problemes i els contextos que resolen. Però, també, en l'adquisició de la matemàtica elemental es necessita practicar una sèrie de rutines que és convenient tenir automatitzades per poder reservar "atenció conscient" a altres aspectes més nobles de les tasques que impliquin decidir, valorar, fer un judici...

Fins i tot, aquest aspecte de realització de tasques rutinàries es veu ara com a menys important, ja que la tecnologia ens ajuda. En concret, en el càlcul elemental 


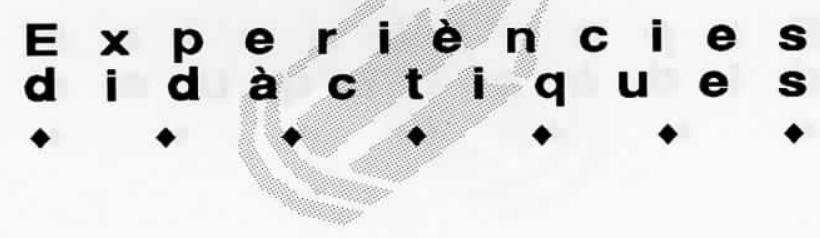

és bàsic tenir sentit quantitatiu i utilitzar el càlcul mental fent les aproximacions adients, $i$ ja no és competència bàsica fer càlculs algorísmics ràpids i descontextualitzats. En canvi, sí que ho és decidir si en aquella situació cal o no fer un càlcul exacte $i$ amb quina tecnologia (llapis $i$ paper, calculadora, full de càlcul) realitzar-lo.

\section{Nous mitjans, millor educació?}

Aquestes noves fites que ens planteja l'educació matemàtica es deuen també al nou "utillatge" de què disposem per fer matemàtiques. Com hem de considerar ara important calcular amb algorismes llargs si aquesta capacitat està implementada en estris diversos que portem al damunt? Vol dir això que no cal saber calcular? No, de fet, la definició de competència bàsica que utilitzem cita el càlcul explícitament, però cal assolir sentit quantitatiu, decidir, valorar el resultat, i això implica capacitat de calcular amb sentit, no d'una manera mecànica i prou. Vol dir entendre els números, saber relacionar-los, entendre el procediment... per alimentar-se sempre i no només menjar un dia, tornant a la idea de Confuci. Encara que la fita sembli elevada, cal ser optimistes. Les noves tecnologies, en part culpables de deixar-nos fora de la tranquil-litat de les classes de pràctica d'algorismes, ens aporten una finestra oberta al món dels recursos, de les possibilitats de diferents maneres de fer, $d^{\prime}$ 'intercanviar (o simplement copiar) activitats i planificacions que podem fer servir de model, a investigar i compartir resultats $\mathrm{i}$ angoixes amb... En aquest sentit, em referiré ara a l'educació matemàtica ajudada de les possibilitats de càlcul, de representació i de simulació que aporta el nou programari.

Després d'uns anys d'incidència desigual del programari educatiu, sembla que ara, amb decisions com el projecte $1 \times 1$, la cosa agafa una altra dimensió. Del mediador llibre de text en paper es podrà passar al llibre electrònic! No conec cap treball seriós que indiqui que el llibre de text de matemàtiques és imprescindible per a l'alumne en qualsevol etapa obligatòria. Més aviat $m$ 'inclino a pensar que, com que estan tan plens de coses (aprofitat al màxim qualsevol raconet de cada pàgina) i ho diuen tot d'una manera tan perfecta $i$ acabada, els alumnes per si sols entenen poc aquell discurs, i la majoria només es fixa en la fórmula que cal aplicar en els exercicis que hi ha al final del tema. Agafen, així, la idea que qualsevol situació o problema tindrà una formuleta que el resoldrà, cosa que porta més a un sentit equivocat de l'activitat matemàtica com a pensament, idees que vénen i que van, que impliquen fer hipòtesi i refutacions..., encara que sigui a un nivell molt elemental però també molt humà des dels primers nivells d'escolaritat. Per tant, el llibre de text en paper era i és bastant prescindible (es veu més convenient un quadern d'activitats adients per practicar, per visualitzar, etc.). Els llibres de text virtuals poden tenir, doncs, els mateixos defectes que els llibres en paper. $O$ si estan ben pensats i si les activitats són més obertes i estan ben plantejades, poden ser millors. El format no ens dirà el què.

Algunes coses sí que ja es pot afirmar que es faran diferent. $\mathrm{Si}$ fem activitats mecàniques (pràctica de certes rutines), el llibre electrònic ens les corregirà més fàcilment $\mathrm{o}$, fins i tot, no ens deixarà fer l'error, ja que no acceptarà la solució equivocada que intentem donar. També pot ser que, malgrat ser una activitat mecànica (pràctica de les taules de multiplicar, per exemple), estigui programada de manera dinàmica o es presenti en forma de joc $i$ tingui, per tant, algun element de motivació extra. Molt més interessant, si cerquem competència, és ajudar els alumnes a visualitzar els números i les relacions que es donen. (Si no recordem la taula del sis podem pensar com es relaciona amb la del cinc? I amb la del tres?) । això sí que pot estar molt ajudat per activitats virtuals ben pensades. Per a primària i primers cursos d'ESO ja hi ha multitud de miniaplicacions (applets) didàctiques molt interessants. Aquestes han estat elaborades per docents del nostre país o d'altres països, per investigadors, per centres de recerca en educació matemàtica. Són les possibilitats més potents de cara a un canvi. A més, hi ha programari potent de cara al treball matemàtic per poder manipular i fer entendre conceptes, ajudats de representacions geomètriques $\mathrm{i}$ representacions algebraiques com és el GeoGebra, que té el mèrit, a més de ser programari lliure, d'estar contínuament millorant i adaptant-se, gràcies al treball entusiasta de professors i professores que el contrasten cada dia amb els seus alumnes en diferents països.

\section{Utilització de miniaplicacions}

De les reflexions anteriors es pot inferir que els professors estem ara davant d'un ampli camp de recursos que hem de conèixer i valorar per triar-los, o no, en funció dels objectius que ens hagin fixat en el curs o nivell corresponent. Em referiré fonamentalment a les 


\section{E.}

miniaplicacions contingudes a tres planes web que, pel fet de ser d'organismes de recerca en educació matemàtica, tenen una estabilitat en el temps; en principi, com que es tracta d'investigadors, se'ls hauria de concedir un cert grau de fiabilitat en la qualitat didàctica de les activitats o manipuladors que han simulat. D'aquestes tres planes, dues es mantenen des dels EUA i es corresponen als coneguts Principles and Standards for School Mathematics recollits pel NCTM i que es reflecteixen de manera clara en l'actual currículum del Departament d'Educació per a aquesta àrea. Les minaplicacions a què em refereixo apareixen a la plana: http://illuminations.nctm.org/ActivitySearch.aspx

Es visualitzen a l'apartat d'activitats i es pot triar el nivell des d'educació infantil fins al grau 12. Els nivells 1-6 es corresponen aproximadament a l'etapa de primària d'aquí. La plana està en anglès.

Una altra base de miniaplicacions similar és a la plana: http://nlvm.usu.edu/

Es tracta d'una pàgina web que manté la Universitat Estatal d'Utah. El primer que hi veiem és un quadre de doble entrada indicant els nivells d'una banda i els blocs curriculars de l'altra, amb el mateix criteri dels estàndards curriculars de l'apartat anterior. Fent clic a la casella producte que interessi s'obren una gran quantitat de miniaplicacions. Aquesta plana es pot agafar en espanyol $i$ els mateixos autors la denominen "manipuladors virtuals".

La tercera plana a què em referiré és d'àmbit europeu, i és la del conegut centre de recerca en educació matemàtica i educació en ciència, l'Institut Freudenthal, que pertany a la Universitat d'Utrecht, a Holanda. Aquest centre ha estat fundat pel professor Hans Freudenthal, que ha estat la veu que ha marcat l'orientació de l'educació matemàtica. Entén la matemàtica com a "activitat organitzadora de l'experiència humana". i té en consideració els processos de matematització horitzontal i vertical, que són la font del llenguatge actual de la competència matemàtica (com es recull a les influents proves PISA). Té, per tant, una orientació del treball de matemàtiques escolars molt fonamentat en la funcionalitat que cerca la comprensió i la competència. Una primera entrada a les miniaplicacions es pot fer a partir de:

http://www.fi.uu.nl/en/cat/
Ens sortiran unes quantes miniaplicacions en català per als nivells d'educació primària. D'allà mateix podem anar a la versió en anglès $i$ als nivells de primària, o de secundària, o a la plana principal del centre de recerca. En la traducció a l'anglès ja hi ha moltes miniaplicacions, però el panorama es tindrà complet si es tria, des de la plana en anglès, anar a la versió en holandès ( $g o$ to ducht site).

\section{Com cal navegar en aquest mar de recursos?}

Mereixen realment la pena? En quin moment $\mathrm{i}$ com puc fer que els alumnes els utilitzin?

Aquestes són les respostes que cada professor i professora del nivell corresponent ha d'anar resolent. De moment, caldrà començar per conèixer-los. Obrir-los i manipularlos, si més no, els que estan en les llengües que coneixem. De manera general, cal dir que cada miniaplicació modelitza una activitat concreta o conjunt d'activitats bàsiques en l'aprenentatge de les matemàtiques, que lògicament es beneficien de les possibilitats d'aquesta tecnologia: imatge, animació, interacció amb l'usuari. Però, com que són activitats dissenyades per investigadors, són a més "models de bona activitat" i, per tant, com a professors ens poden servir, en primer lloc, per saber quines activitats hauríem de plantejar als alumnes $i$, si de moment no tenim un accés tan fàcil a la nova tecnologia, podem implementar la mateixa activitat en altres formats. Això passa principalment per les activitats pensades perals primers nivells escolars, no tant en les activitats dissenyades per a l'ESO, on la substitució del format ja no és possible.
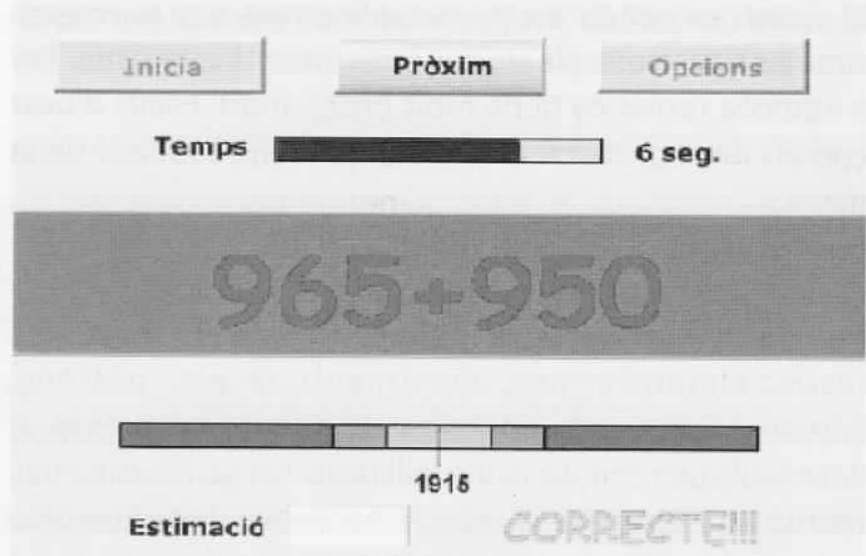

Aplet per fer estimació de resultats, plana: http://deim.urv.cat/ /luisa.girondo/ 


\section{E.}

Alguns ens interessaran per manipular conceptes. Ajudats de la visualització es pot donar sentit, per exemple, al producte de fraccions, tema que es ben feixuc si no es té un simulador electrònic. Mireu per a això fraccions, multiplicació rectangular:

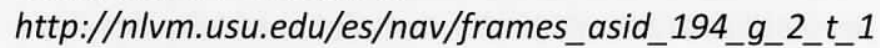
.$h t m l$ from =category_g_2_t_1.html

D'altres són molt adequats perquè els alumnes practiquin les taules d'una manera relacional. Es pot demanar que ho practiquin a casa. És el cas de la miniaplicació stamps (versió en anglès):

http://www.fi.uu.nl/toepassingen/00018/toepassing_re kenweb.xml?style $=$ rekenweb\&language $=e n \& u s e=$ game

Altres els utilitzarem com a complement d'activitats manipulatives. Per exemple, l'àbac de dos colors per representar quantitats i codificar-les numèricament per treballar amb els alumnes de primer curs de manera simulada, ja que es fa tot alhora, el mateix que es pot fer a classe manipulant les fitxes de l'àbac i representant les quantitats amb els cartronets de valor de posició. http://illuminations.nctm.org/ActivityDetail.aspx?ID $=8$

Alguna temàtica, com pot ser el càlcul aproximat en els nivells bàsics, millora molt si es practica mitjançant programari, ja que es necessita un controlador que li digui al practicant de quin ordre és la seva aproximació (o si es pot millorar). Per a aquest aspecte, podeu consultar algunes miniaplicacions de la plana:

http://deim.urv.cat/ /luisa.girondo/Applets_PFC1/class es/Principal1.html

El mateix es pot dir de les minaplicacions que permeten simular situacions aleatòries $i$ tractament estadístic. Per a aquesta temàtica hi ha molt programari. Fàcils d'usar són els de l'apartat Anàlisi de dades i probabilitat de la plana:

http://n/vm.usu.edu/es/nav/vlibrary.html

En referència a qüestions geomètriques (especialmentformes, moviments al pla, patrons, construccions amb policubs...), que corresponen al desenvolupament de la visualització i al sentit espacial, també en les planes citades hi ha moltes activitats que es poden combinar amb activitats de manipulació física a l'aula.
Amb aquesta breu descripció ja imagino que haureu obert les planes $i$, si no de manera immediata, heu guardat l'enllaç per tornar-hi amb més calma. Ara, per acabar, voldria referir-me a dos aspectes més.

El primer és que, davant la imminent aparició al pupitre escolar de l'ordinador, cal pensar com aquest afectarà l'educació matemàtica del ciutadà. Per on caminaran els nous "textos" virtuals? Si han de ser inadequats (molts exercicis rutinaris, activitats molt tancades, descontextualització...), no cal ni pensar-hi. Ara hi ha material suficient a la xarxa perquè cada professor, o equip de professors, es prepari la seva carpeta de "matemàtiques" amb recursos i activitats adaptades a laseva realitat.

El segon és que, gràcies a la "internacionalitat" del llenguatge matemàtic, podem tenir tants recursos al nostre abast (fins i tot sense un gran domini d'altres llengües), però la competència matemàtica necessita eines ben compreses i molt raonament adaptat al context. I aquí hi ha la segona part de la feina: quines situacions de context no matemàtic són les que cal utilitzar per donar sentit aplicatiu?; quins problemes pràctics cal utilitzar? També a la xarxa es poden trobar idees, però ja no són tan importables; si més no, cal saber adaptar-les al nostre entorn cultural, a les necessitats d'uns alumnes concrets.

Aquestes són algunes de les coordenades en què es mourà la tasca dels professors de matemàtiques els pròxims cursos amb la bona intenció de millorar la competènciamatemàtica de les joves generacions.

Notes

(1) www.europarl.europa.eu/sides/getDoc.do?pubRef=//EP//TEXT+Ta+P6-TA-2006-0365+0+DOC+XML+VO//ES

(2) http://www.casaasia.es/matematicas/

\section{Referències}

Niss, M. (1998), a Puig, L. (coord.): Investigar y enseñar. Variedades de la educación matemática. Bogotá: Una Empresa Docente

Penrouse, Roger (1991). La nueva mente del emperador. Madrid: Ed. Mondadori.

Wassenberg, Jorge (2004). La rebelión de las formas. Barcelona: Tusquets editores. 